\title{
Understanding local attitudes to the utilization of public infrastructure services: The case of rural electricity services in Akwa Ibom state, Nigeria
}

\author{
Nseabasi S. Akpan \\ Department of Sociology and Anthropology, Faculty of Social Sciences, University of Uyo, Uyo, Akwa Ibom State, Nigeria \\ Email address: \\ akpan.nseabasi@ymail.com \\ To cite this article: \\ Nseabasi S. Akpan. Understanding Local Attitudes to the Utilization of Public Infrastructure Services: The Case of Rural Electricity \\ Services in Akwa Ibom State, Nigeria. Humanities and Social Sciences. Vol. 2, No. 4, 2014, pp. 114-120. \\ doi: 10.11648/j.hss.20140204.14
}

\begin{abstract}
This paper examines local attitudes to the utilization of public electricity services in rural Nigeria using Akwa Ibom State as a case study. The idea is anchored on the broad theoretical and empirical discourses on the relationship between public infrastructure and development. A wide range of study approaches, including observation and physical monitoring, random and purposive interviews and personal backgrounds of research and development project implementation experiences in the study area, was utilized. Findings showed that electricity coverage for rural areas is not only low, its utilization scope was equally low and limited. This was attributed to poverty, a lack of economic specialization, limited exposure and knowledge of community members to a range of electricity service application channels. It was equally discovered peoples' attitudes to public electricity services boiled down to the usual attitudes of seeing public infrastructure services as 'freebies'. Implications on cost recovery and sustainability have been discussed with necessary recommendations.
\end{abstract}

Keywords: Public Power Infrastructure, Electricity, Attitudes, Utilization, Rural Nigeria

\section{Introduction}

Over the years, investments in public physical, social and economic infrastructures have formed the fundamental basis for spatial and socio-economic development practices. This is because infrastructures contribute to the processes of production, processing and distribution in ways that lead to the overall improvement of the economic and social development systems as well as improving the quality of human lives and livelihoods. Investment in public infrastructures has been known to influence the course of development through several radiating and secondary benefits (Hirschman 1958, Perroux 1955). One area of such benefits is its capacity to create adequate conditions for the growth of new businesses and attraction of firms to less developed areas.

Padjen (1996, in Botrić et al 2006) has identified three theories that explore the relationship between infrastructure and development namely: development through a surplus infrastructure, development through a deficit of infrastructure and balanced development. When there is a higher concentration of infrastructure over production capacity, it is often assumed that infrastructure will have an initial and inductive role in economic development. This assumption is anchored on the fact that the existence of infrastructure is a prerequisite for the development of other activities. The logic of initial concentration of infrastructure as an avenue of attracting development is still being utilized in most developing and emerging economies including Nigeria. However, this approach has been criticized through empirical findings suggesting that such initial causation does not hold in most cases, that is infrastructure on its own cannot fully guarantee development (Botrić et al 2006). The other angle in the relationship between infrastructure and development works on the assumption that a growth in economic production and development has a tendency to attract public or private investment of infrastructures. This is a logical development route that feeds on the assumption that economic production alone has the capacity to attract and speed up investment in infrastructure thereby reinforcing growth potential. This approach is mostly applicable in developed 
countries. Balanced development on the other hand is focused on the idea that only the simultaneous development of infrastructure and production is sustainable. This aspect emphasizes the fact that infrastructure forms an integral mix in the production process and its overall function is to enhance economic growth.

The relationship between infrastructure and development has long been theorized and empirically discussed. A discussion by Zhao and Kanamori (2007: 5), citing a number of authors, clarified such relationship as follows: 'Nicholas Stern (1991) emphasizes in particular the importance of infrastructure, management and resource allocation in economic growth. He states, 'the deficiencies of infrastructure, together with the weakness of management and economic organization, are likely to account for a substantial part of low factor productivity in developing countries.' 'it is very hard to run factories and businesses effectively when electricity and water supplies are unreliable, the telephone and mail services are weak, and transport is slow, costly and hazardous.' In explaining why the growth of the Indian economy has been slower than that of the Chinese economy, Bhalla (2002) points out that inadequate infrastructure, multiplicity of objectives, bureaucratic procedures, and limited power of the local authorities and uncertain and unpredictable investment incentives all contribute to the difference.

From available theoretical discourses, it is clear infrastructure is the pre-requisite for the development of any economy. Greater access to it is necessary for spatial and social development. However, empirical studies on the relationship between infrastructure and development do take very broad perspectives by focusing on so many issues without highlighting the contribution of specific elements of infrastructure to development. Beyond this argument, it is important to stress that infrastructure availability on its own hardly satisfies or catalyzes the needed development without its proper utilization, which is further tied to the right attitudes and entrepreneurial resources of the people. This study intends to contribute empirical knowledge in this perspective. The study specifically focuses on the relationship between electricity services utilization and rural development in Akwa Ibom state, Nigeria. Provision and access to electricity services are often seen as important to the development of rural areas but how do the intended beneficiaries of electricity perceive the services and what attitude characterizes its utilization? These and related questions will be addressed.

\section{Nigeria's Public Infrastructure Scenario: The Urban and Rural Dichotomies}

A great majority of Nigeria's population resides in the rural areas. For instance, the 1963 Census recorded 80.7\% of the national population as rural residents. By 1985, the proportion had slightly gone down to $70.13 \%$ and was estimated that a further drop to $69 \%$ in the proportion was expected in the 1990s (Muoghalu, 1992). In 2005, it was estimated that $53 \%$ of the Nigerian populace resides in the rural areas (World Development Reports, 2005) and in 2011, the world Bank reports recorded $51.6 \%$ of Nigeria's rural population. The general consensus seems to be that the rural areas in Nigeria are very heavily populated. Agriculture is the mainstay of the economy, contributing about 45 per cent of GDP. The agriculture sector employs about two-thirds of the country's total labour force and provides a livelihood for about 90 per cent of the rural population.

Despite Nigeria's plentiful agricultural resources and oil wealth, poverty is widespread in the country and has increased since the late 1990s. Over 70 per cent of Nigerians are now classified as poor, and 35 per cent of them live in absolute poverty (IFAD, 2011). Poverty is especially severe in rural areas, where up to 80 per cent of the population lives below the poverty line, and social services and infrastructure are limited. Rural infrastructure in Nigeria has long been neglected. Investments in health, education and water supply have been focused largely on the cities. As a result, the rural population has extremely limited access to services such as schools and health centers, electricity and about half of the population lacks access to safe drinking water.

Despite the fundamental contributions to the national economy, the rural areas are not attractive to live in, given the general absence of basic infrastructures (potable water, roads, electricity, healthcare systems, and financial institutions, among several others) and poor quality of life occasioned by persistent poverty. Attempts at solving the rural problems had been the concern of the governments over the years. Several programs such as Operation Feed the Nation (OFN); the National Accelerated Food Production Program (NAFPP) and the Directorate for Food, Roads and Rural Infrastructure (DFRRI), National Economic Empowerment and Development Strategy (NEEDS), among others, have been witnessed most especially at post-independence era.

The structural adjustment program, for instance, witnessed the establishment of the Directorate for Food, Roads and Rural Infrastructure (DFRRI) in 1985 for the purpose of providing rural infrastructures in the country side. The laws establishing the directorate was promulgated under decree number four of 1987. The core of the Directorate's program was to promote productive activities. Besides, the directorate recognized the provision of rural infrastructure such as feeder roads, water, electricity and housing as essential for the enhancement of the quality of life in the rural areas. Electricity was particularly emphasized to facilitate industrial growth, and improve the attractiveness of the rural environment for investments.

Subsequent efforts at rural development came in the light of Nigeria's democratic dispensation (1999-to date). A fouryear development plan was initially articulated (1999-2003) with the objective of pursuing a strong, virile and broad- 
based economy that is highly competitive, responsive to incentives, private sector-led, diversified, market-oriented and open, but based on internal momentum for its growth (Marcellus, 2009 cites Donli, 2004). The National Economic Empowerment and Development Strategy was one such program that emphasized, among other issues, rural electrification. NEEDS was quite comprehensive and ambitious, as it was not only duplicated at all levels of governments (State Economic Empowerment and Development Strategy-SEEDS; and Local Economic Empowerment and Development Strategy-LEEDS), it incorporated the private sector, non-governmental organization and the general public in pursuits of its developmental goals. As a framework for poverty reduction and for the stimulation of economic growth, NEEDS' key objective was to facilitate a broad-based based market oriented economy that will involve active participation of the private sector, with the main source of economic empowerment coming from the generation of gainful employment opportunities as well as the provision of social safety nets for vulnerable groups. Rural electrification was strongly emphasized in NEEDS but the question is how have these efforts influenced local perceptions and utilization of public infrastructures?

\section{The Nigerian Power Sector}

The Nigerian power sector is driven by hydro electricity. The major generating sectors include: Kainji, Jebba, Shiroro, Egbin, Ajaokuta, Sapele, Afam, Delta, Okpai, Aes, Ijora, Calabar and others. Over the years, the performance of the Nigerian power sector has been significantly very poor. Electricity coverage is generally low and is worse for rural areas despite immense budgetary allocations. Based on Young (2005), Nigeria still has a very dismal performance in the power sector as the energy use per person is very low (with $85 \mathrm{kWh} / \mathrm{cap} /$ year) compared to other countries in Africa such as Cameroon (184 Kwh/cap/year) and Egypt (with $900 \mathrm{kWh} / \mathrm{cap} /$ year) among other countries (Table 1)

Table 1. A comparative Analysis of Energy Use Per Person in Africa

\begin{tabular}{ll}
\hline Countries & Energy Use Per Person $(\mathbf{k W h} / \mathbf{c a p} / \mathbf{y e a r}$ \\
\hline Cameroon & 184 \\
Nigeria & 85 \\
Ethiopia & 21 \\
Kenya & 126 \\
Tanzania & 55 \\
Uganda & 38 \\
Burkina Faso & 29 \\
Ghana & 204 \\
Senegal & 114 \\
Algeria & 581 \\
Egypt & 900 \\
Morocco & 430 \\
World Average & 2108 \\
\hline
\end{tabular}

Source: Young (2005)
Nigeria develops $23 \%$ of her feasible hydropower. This is very low compared to other African countries such as Lesotho (50\%); Bukina Faso (46\%); Kenya (34\%) and others (Young, 2005). Social infrastructure provision finds expression in the theoretical position and arguments for the existence of public goods, natural monopolies, merit goods and externalities. These are terminologies principally aimed at addressing the needs of every layers in the society (Ilori, 2004). For instance, no private concern would be willing to invest in large scale ventures that may be difficult to recoup such investments (e.g. public power supply). Considering varying demands and capacities, State involvement becomes necessary especially when the poor has to be accounted for through cross-subsidization or general State subsidy. State action becomes important for economic development as well as the provision of enabling atmosphere for private sector economic investments.

Over the years, the provision and growth of public utilities have become essential in Nigeria as government got involved in almost all sectors of the economy providing services, which include power supply. The Power Holding Company of Nigeria (PHCN) is statutorily charged with the generation and distribution of power for residential, industrial and other commercial uses. So far there has been consistent public outcry bordering on the poor and depreciating quality of services rendered by the Authority. For instance, Ilori (2004) reported that the energy generation availability in Nigeria declined to $1600 \mathrm{MW}$ in 1999 from 5,876 MW installed capacity with only 19 functioning out of the 79 generating units. Ilori (2004) further observed that existing Radar Transmission lines were completely run down. Many transformers and circuit breakers had not been maintained for years, inspite of clear cases of overloading which frequently render the facilities vulnerable and susceptible to regular breakdown. Fluctuating decline in investments, inefficiencies, corruption and sabotage have always been held responsible for these. Currently, the estimated demand for power in 2005 and 2010 are respectively put at 9,780MW and 20,000MW. At the moment generating capacity are reported to be less than $4000 \mathrm{MW}$, showing that the possibilities of meeting this targets remain bleak.

\section{Study Approach}

This paper is based in Akwa Ibom state, and it is a product of over five years of keen and casual observation and physical monitoring, random and purposive interviews as well as ocasional participation in community development activities and project implementation. The long term rich experience of the researcher as a rural sociologist and as one who maintains deep and regular family relationship in the rural areas have been useful in building this project. The interplay of keen observations, experiential background, informal interviews were useful in: 1) capturing a range of electricity use and consumption activities within a given household; 2) gaining insights on 
local attitudes towards the utilization of such infrastructure; 3) and many other issues relating to the wider social, economic and governance aspects of public electricity supplies and consumption in Nigeria.

In all, about 10 rural communities were used as the basis of this study. The choice of the communities was made to reflect the wider geographical diversity of the State. Consequently, specific focus areas were Ibeno, Ikot Abasi and Esit Eket (southern region of the state); Itu, Ini and Obot Akara (northern section of the state) while the remaining four communities came from Nsit Ibom, Nsit Ubium, Nsit Atai and Ibesikpo Asutan (the middle part of the state). Previous research activities in these communities used simple interviews, focus group discussions, keen observation and some secondary review. These information and data have formed the basis for estimation and generalization. There were, however, subsequent follow-up interview checks to strengthen available data. Key issues of interest include access to public power supplies, regularity of supply, level of utilization, average monthly tariff, responsible agencies, utilization attitudes, among several other variables. These variables provided the basis for discussion purposes.

Findings emerging from this study is dominantly qualitative given its exploratory nature. It is also important to state that rural electrification projects in Akwa Ibom state, though spanning from the $80 \mathrm{~s}$, practically manifest at a relatively improved scale during the democratic dispensation beginning from 1999. This implies that the greater percentage of rural households do not have access to electricity services. Some of these issues are, however, acknowledged as limitations. Despite the limitations, the results really give a fair representation and estimation on the nature of access and coverage as the basis for discussing attitudes toward utilization.

\section{Results}

\subsection{Coverage and Access to Public Power Supply in Rural Akwa Ibom State}

Observations and estimation generally suggest quite low coverage and access to public electricity services among rural dwellers in Akwa Ibom state. On average less than $20 \%$ of the rural population enjoy functional electricity supply. Households in this category are likely to have electricity service during general supplies from the responsible agency, i.e., Power Holding Company of Nigeria (PHCN). It was further observed that some communities (about 12\%) had long benefitted from connection services in their different homes, yet actual supplies of electricity have not been possible. For such communities, availability of electric cables and poles had enabled few connections to different homes (for the financially capable households), but without actual power supplies. The village leader in one of the communities observed, 'these poles and cables were installed since 2003, giving us endless expectation of electricity, which has never materialized uptil now...no hope at all as it is...'

Households' access to electricity was noted to be highly limited to lighting points, accessed through the neighbourhood. Conequently, most connections hardly passed through the main connection points largely due to cost limitations. Connection preferences depend largely on informal channels, which typically would only be linked to a single room or at most two lighting points. Such informal connections were noted to be mostly facilitated by the most enlightened member of the household most likely the male adolescent or adult. Households who depend on informal channel to access public electricity supply use such service for lighting and music entertainment. Extremely few households were able to fully equip their residence with public electricity connection. Income, wealth and status were a factor that accounted for full utilization of public electricity services. Hosueholds who afforded full access to public electricity lived in modern houses (equipped with electronics such as television, sound system, refrigerator, fan and in some cases air conditioners). Such households were relatively well-to-do with high income, education and relative exposure.

Some rural communities were noted to enjoy improved public electricity services, even over their urban counterparts. For instance, most communities in Ibeno, Ikot Abasi and Itu spoke of relatively improved electricity services than others in Ibesikpo Asutan, Nsit Ibom, Ini, Obot Akara, etc. Such disparities in electricity service regularity and quality had to do with their relative location which placed them in advantage position relative to others. Ibeno, Ikot Abasi, for instance are powered by the Exxon Mobil and Aluminium Smelter Company of Nigeria (ALSCON) respectively (as part of their Corporate Social Responsibility) while Itu enjoys the advantage of close proximity with the main high tension public power source. Beyond these basic advantages and extra supports, most other rural communities either do not have access to public power source or their connections and supply services were highly irregular. Relatively well-to-do households with full connection services ocassionally depend on private generating plants to supplement public supplies. According to one interviewee (who should be in his 50s), '...now we have been exposed to electricity services and our houses equipped with some electronics, you discover you cannot stay for some days if there is no service...you have to still enjoy watching films, drinking cold water and many others...' This statement directly lent support to the imperative of running a private generating plants.

How is access to rural electrification services financed? This important question enabled an understanding of the various channels through which rural electrification services are provided. Services were discovered to come from diverse sources of supplies under various schemes of community development services. The government of Akwa Ibom state dominated rural electricity service provision either directly through the various ministries, 
agencies and parastatals or indirectly through some forms of supports to international, national and non-governmental organizations. Most communities derive their electricity infrastructure through the national agencies of governments e.g., the Niger Delta Development Commission (NDDC), a federal agency, has been involved in diverse forms of rural and community development schemes, which electricity provision is an important element. Multinational petroleum organizations such as Exxon Mobil, SHELL, ALSCON, etc., also provide electricity services to rural communities in the forms of corporate social responsibilities. The study equally identified some World Bank electricity infrastructure projects. Communities were also noted to fund their electricity project either through collective efforts or in partnership with non-governmental organizations and the State etc. Whichever channels of access to electricity, responsibilities for tariff collection and management of services ultimately rests on the Power Holding Company of Nigeria (PHCN). One characteristics of rural electricity services has to do with the prevalence of poor cost recovery for services provided. Some communities visited claimed they have never been paying electricity bills. Others said most service users rarely pay bills.

A number of factors were responsible for poor cost recovery for electricity services provided. For instance, most respondents' economic and financial backgrounds were incapable of supporting monthly subscription to electricity services. A lack of financial capability was the major reason why most rural households were unable to obtain direct services of electricity from the main connection point. Most households opted, instead, to depend on indirect and illegal connections. Few others who enjoy direct connection could not see the need to be paying for monthly subscription. A respondent (in his 50s and occupying a modern house) had this to say in response to the question on attitude toward electricity bill: 'electricity bill? That will depend on if NEPA [the old acronym for PHCN] supplies light...I will not be prepared to be spending on services that I rarely use...' Communities who expended resources and efforts in securing access to public power infrastructure equally did not see the need for recovering cost of services. This attitude is linked to the prevailing grievances of long-term rural neglect and massive poverty inspite of their importance in providing natural resources to the development of urban areas. Such communities mostly perceive public services infratructures as compensatory and part of their share of the national and state development benefits.

\subsection{Utilization and Attitudes to Public Electricity Infrastructure}

Generally, the utilization of electricity services in rural areas remains poor and extremely limited. Public electricity services mostly function for lighting services. Every households and respondents made references to this aspect of electricity services. Beyond 'lighting' needs, few equally depended on electricity services for music entertainment. An estimated $30 \%$ of the respondents who had access to public electricity fell into this category. A very insignificant percentage of the respondents depended on electricity services for diverse forms of utilization. This category of the respondents neatly fit into those households who had direct and full connections (and living in modern houses). The tendency for using electricity services for economic production purposes were, however, observed most especially in communities with relatively long-term and stable supplies e.g., in some communities in Ibeno, Ikot Abasi and Itu. Beyond these communities, the utilization of electricity services for economic production was highly limited and exceptional to return migrants from cities. Households living in modern houses with refrigerators ocassionally offer sales of refrigerated items of mainly cold drinks for few who can afford. Beyond this, local smallscale businesses especially welders, tailors, hairdressing and barbing saloons etc utilized electricity for their respective services.

Limited scope for utilizing public electricity services among rural communities in Akwa Ibom state could best be attributed to poverty, a lack of economic specialization, limited exposure, and limited knowledge of community members to a range of application channels etc. Most literatures see the rural populations in Nigeria as extremely very poor, lacking in basic infrastructures and the prevalence of very limited and agrarian-based economic activities, characterized by primitive techniques of cultivation and dominated by the ageing population (IFAD 2011, World Development Report 2005, Olatunbosun 1975, World Bank 2011). In all arguments, Nigeria's rural areas lack the necessary opportunities that could engender the utilization of public electricity services. Households that managed to go beyond mere 'lighting' service to 'music entertainment' application were at the instance of one or two of their adolescent or adult school children who have had some measure of exposure. Such households depended on informal and illegal connection services and hardly were disposed to paying service fees. The argument within this context still goes back to earlier discussion bordering on the link between socio-economic factors (of income, wealth and status) and electricity utilization scope and capacity. As these factors work to the advantage of very few respondents, it implies that the greater majority of rural dwellers are less likely to realize the full social and economic benefits of public electricity services in the nearest future.

The respondents also expressed diverse attitudes toward the utilization of public electricity services. To a large extent, such attitudes developed out of the general socioeconomic limitations that are part of the rural population. Almost all the respondents saw public electricity services as their version of state 'development benefits'. One woman (in her late 30s) had this to say: 'they [the government] themselves know they have cheated us for long time...if they now say we should have light...thank 
God...but they should make it easy for everyone to have it [light] in their different houses...' most respondents fell in the category of this argument: they want the services freely given to them and without subscription charges. These attitudes and mindsets were important explanatory reason for inability to recover cost of services from the responsible agency.

It is also important to understand that prevailing local attitudes toward the utilization of public electricity infrastructure services also have to do with the lack of necessary capacity to realize the full utility value of public electricity services. It would be practically impossible for respondents with practically no skill base beyond subsistent farming practice to pretend knowledge and or take full advantages of the potential encapsulated in electricity services. Rural-urban migration is very strong in Nigeria, among the younger and educated age-groups. The 'aged' and 'ageing' dominate rural agricultural and other activities Such groups lack the capacity in terms of occupational skills and training, and are extremely poor and disconnected from modernity. Electricity services utilization among such group will continue to be very poor as such service would only be perceived from its basic utility perspective of 'lighting' rooms and surrounding environment.

\section{Discussion of Findings}

Clearly, electricity coverage for rural areas in Akwa Ibom state remain very low. Households' access to electricity infrastructure did not translate into functional services as less than $20 \%$ of the rural population enjoyed relatively functional supplies of public power services. Some levels of socio-economic condition including income, education and social status largely explained individual and household abilities to gain access to public electricity services. The high cost of initial installation of electricity cables and associated facilities largely was beyond the reach of the poor and low income earners. Equally important was the fact that most respondents who enjoyed access to public electricity supplies were relatively of improved social and educational status. Such individuals lived in modern houses with some electricty demanding appliances such as refrigerators and other conditioners. Improved economic and social status were the major influential factors for interest in public electricity services which were complemented with private generating plants in most cases.

Few communities, however, enjoyed relatively improved coverage. This was the case of some coastal communities where some multinational companies contributed to rural electrification as part of their corporate social responsibilities. Generally, the utilization of public electricity services was noted to be very poor and mostly limited to lighting points, music entertainment and, in few cases, for household refrigerator services, all depended on individual and household capacities. Very few individuals availed the opportunities of public supply of electricity for commercial and small scale business activities. The use of refrigerator contributed to the emergence of local small scale businesses centering on cold drinks. Few respondents with financial capacity utilized this as their income supplements. From local narratives, the potential of rural electrification in the social and economic transformation of the rural areas remain largely unexplored.

The idea of developing the rural areas has been around for several decades (ODI 2002; Conway 1997). According to ODI (2002), 'rural development should be central to poverty reduction. Three quarters of 1.2 billion people surviving on less than one dollar a day live and work in rural areas. Rural people are twice as likely to be poor as urban counterparts. However, rural development faces a loss of confidence: funding has been falling, and government and donors are scrambling to think policy. What new directions should rural development policy take'? one model that is very central to rural transformation is rural electrification. Massive electrification of rural areas has been advanced as capable of catalyzing several chains of productive economic activities (Hirschman 1958, Perroux 1955). This argument is also in line with studies by Zhao and Kanamori (2007) and Nicholas Stern (1991) which all agreed that rural infrastructural access and utilization are capable of improving the productivity and livelihood of the rural dwellers. This present study, however, demonstrate that rural areas in Akwa Ibom state are less likely to develop given inadequate supply and utilization of public electricity services.

\section{Concluding Remarks}

This study was conceived to assess local attitudes to the utilization of public electricity services in rural Nigeria, using Akwa Ibom state as a case study. Given the long established relationship between infrastructure and development, this study raised some questions bordering on rural electrification coverage and utilization with specific emphasis on how local attitudes to public infrastructure (such as electricity) affect its utilization. From the study findings, local electricity utilization interest among rural dwellers in Nigeria is a function of several socio-economic factors including the level of economic specialization, household socio-economic capacities including income status, lifestyle, exposure and taste factors. Electricity coverage for rural areas is not only low, it was discovered that its utilization scope was equally low and limited, mostly attributed to poverty, a lack of economic specialization, limited exposure and knowledge of community members to a range of electricity application channels. Extremely few respondents had derived relatively wider range of electricity utilization, while the greater proportion utilized it for mere 'lighting' services, with possible prospect of graduating toward 'music entertainment', depending on the household.

Generally, respondents' attitudes to public electricity 
services boiled down to the usual attitudes to government services in Nigeria. Households who had access to public electricity supplies saw such service as a direct means for compensating for long years of rural development neglect and were not favorably disposed to cost recovery plans of government. This attitude itself was reinforced by poor and irregular services of public electricity in their homes and communities. Functional electricity infrastructure in addition to its regular supplies is important for rural development. This link, however, cannot be achieved in the context of poor coverage, irregular supplies and low utilization. Given the result of the study, the paper finds it easy to recommend massive and regular public electricity supply scheme with initial full subsidization plans for the rural population. Such plans could likely attract wider utilization and subsequently has the potential of improving rural utilization attitudes as well as enhancing rural economic development activities.

\section{About the Author}

Nseabasi S. Akpan, PhD, Senior Lecturer, Department of Sociology/Anthropology, University of Uyo, Nigeria. His research interest includes Sociology of Mass Communication, Rural Sociology \& Social Psychology. He has published up to 24 scientific articles. He is a member of World Council on Curriculum \& Instruction, National Association of Sociology/ Anthropology \& Nigerian Rural Sociology Association.

\section{References}

[1] Bhalla AS (2002). Sino-Indian growth and liberalization: a survey. Asian Survey vol 42. No.3, pp.419-439

[2] Botrić V., S. Jelena and L. Śkkuflić (2006). Road infrastructure and regional development: some evidence from Croatia. Prepared for the $46^{\text {th }}$ Congress of the European Regional Science Association, Volos, Greece: August $30^{\text {th }}$-Sept $3^{\text {rd }}$.

[3] Cornway G. (1997). The doubly green revolution. Harmondsworth: Penguin Books.

[4] Donli, J. G. (2004). An overview of Nigeria's economic reforms. NDIC Quarterly, 1 (4): 62-82.

[5] Hirschman AO (1958). The strategy of economic development. New Havens: Yale University Press.

[6] IFAD (2011). Rural Poverty in Nigeria. http://www.ruralpovertyportal.org/web/guest/country/home/t ags/nigeria. International Fund for Agricultural Development.

[7] Ilori, B. (2004). The role of government in the development of basic infrastructure.

[8] Marcellus, I. O. (2009). Development planning in Nigeria: reflections on the National Economic Empowerment and Development Strategy (NEEDS), 2003-2007. J. Soc Sci, 20 (3): 197-210.

[9] Muoghalu, L. N. (1992). Rural development in Nigeria: a review of previous initiatives. In Olisa, M. S. O. and Obiukwu, J. I. (eds). Rural development in Nigeria: dynamics and strategies. Mekslink Publishers. Awka.

[10] ODI (2002). Rethinking rural development. ODI briefing paper. Overseas Development Institute, London. March. www.odi.org.uk

[11] Olatubosun, D. (1975). Nigerian neglected rural majority. Ibadan: Oxford University Press.

[12] Padjen J. (1996). Prometna politika. Zagreb: Informator I Ekonomski Institute, Zagreb. Cited in Botrić V., S. Jelena and L. Śkuflić (2006). Road infrastructure and regional development: some evidence from Croatia. Prepared for the $46^{\text {th }}$ Congress of the European Regional Science Association, Volos, Greece: August $30^{\text {th }}$-Sept $3^{\text {rd }}$.

[13] Perroux F. (1955). Cited in Oguzor NS (2011). A spatial analysis of infrastructures and social services in rural Nigeria: implications for public policy. GeoTropico, 5 (1), Articulo 2: 25-38.

[14] Stern N. (1991). The determinants of growth. Economic Journal 101: 122-133.

[15] World Bank (2011). Cited in IFAD (2011). Rural Poverty in Nigeria.

http://www.ruralpovertyportal.org/web/guest/country/home/t ags/nigeria. International Fund for Agricultural Development.

[16] World Development Reports (2005). Cited in IFAD (2011). Rural Poverty in Nigeria. http://www.ruralpovertyportal.org/web/guest/country/home/t ags/nigeria. International Fund for Agricultural Development.

[17] Yakubu, O. D. and J. A. Aderonmu (2010). Rural poverty alleviation and democracy in Nigeria's fourth republic (1999-2009). Current Research Journal of Social Sciences 2 (3): 191-195.

[18] Zhao Z. and T. Kanamori (2007). Infrastructure and regional development in the People's Republic of China. ADB Institute Discussion Paper No. 69. 